\title{
AN UNUSUAL CUTANEOUS REACTION IN MENTAL DEFECTIVES AFTER VOLE BACILLUS VACCINATION BY MULTIPLE PUNCTURE AND ITS TREATMENT
}

BY

\author{
J. A. H. WYLIE, D. H. BENNETT, AND J. SWITHINBANK \\ From the Sir William Dunn School of Pathology, Oxford, the Fountain Hospital, London, and the Department of Surge \\ the Radcliffe Infirmary, Oxford
}

(RECEIVED FOR PUBLICATION JANUARY 6, 1954)

Vole bacillus vaccination has been used extensively in recent years in carefully selected groups and communities. For reasons stated in detail by Wells (1946), the great majority of the earlier trials were conducted and are being followed up in institutions for the mentally defective. These provide a comparatively static population, permitting not only long-term assessment of the capacity of the vole bacillus to increase resistance to tuberculosis but also early detection and treatment of any undesirable sequelae.

The local skin complication which occasionally arises after vaccination with the vole bacillus by multiple puncture reported here may be both unsightly and persistent. It has been seen only in mental defectives and never in any normal person. The lesion is discrete, arising from one or more of the 40 individual punctures, or coalescent, involving a part or the whole of the vaccinated area. Only very rarely does it extend beyond. It resembles the "apple jelly" consistency of lupus vulgaris in its early stages. The affected area is raised $2-3 \mathrm{~mm}$. above the surrounding healthy skin, and is a rosy pink. The impression is of delicate granulation tissue peculiarly vulnerable to trauma and covered by thin overlying skin. The lesions may break down at one point and sometimes involve the whole vaccinated area, producing an ulcer with a moist, though purulent or necrotic, base.

Histologically the lesion shows a typical and consistent picture. Large epithelioid cell systems are present, usually exhibiting several giant cells of the Langhans type. Necrosis is very seldom seen and histologically we have never found acidfast bacilli. Repeated culture has failed to yield any vole bacilli. This is not altogether surprising as the vole bacillus is dysgonic on all laboratory media, especially in small inocula. Very few of those vaccinated who showed a lupoid reaction had palpably enlarged lymph nodes and none abscess formation.

\section{INCIDENCE OF LUPOID REACTION}

Table I shows the proportion of persons under and over 10 years who developed a lupoid reaction after multiple puncture vaccination. The most important single factor in the development of $\vec{q}$ lupoid reaction seems to be secondary infectio Mental deficiency leading to hospital admission $\mathrm{fh}$ a young child is either profound or is complicated by some physical handicap, and in any case cis almost invariably associated with incontinence of faeces and urine. The supervision of the children is more difficult than that of adults and in most institutions is further handicapped by shortage \&f staff. The opportunities for secondary infection are, therefore, high.

TABLE I

LUPOID REACTIONS IN RELATION TO VOLE BACILLUS

\begin{tabular}{|c|c|c|c|}
\hline Age Group & & $\begin{array}{c}\text { No. of } \\
\text { Vaccinations }\end{array}$ & $\begin{array}{l}\text { No. of } \\
\text { Lupoid Reactiong }\end{array}$ \\
\hline $\begin{array}{l}\text { Under } 10 \text { years ... } \\
10 \text { years and over }\end{array}$ & $\begin{array}{l}\ldots \\
\cdots\end{array}$ & $\begin{array}{r}512 \\
1,710\end{array}$ & $\begin{array}{l}30(5.9 \%) \\
44(2.6 \%)\end{array}$ \\
\hline
\end{tabular}

In some cases the eruptive stage after vœe bacillus vaccination is associated with pruritüs which leads to scratching of the papules and $\Phi 0$ their subsequent infection. The pruritus, if atte tion is drawn to it by a normal child or by the observation that the patient is scratching, can $\overline{\mathrm{Be}}$ effectively alleviated by the application of ameth8caine ointment (Hall and Wylie, 1952). One seris of vole bacillus vaccinations, though small, strimsingly demonstrates how secondary infection favouws the development of the lupoid reaction. The chisdren vaccinated were from special schools afd classified as "educationally subnormal" but n\&t certified as mentally defective. These children are of higher intelligence than those previously d $\overline{\mathrm{s}}$ cussed and although requiring care and protection are capable of benefiting from special educationit methods. Girls and boys from these schools we 
vaccinated on being found tuberculin negative. The boys were all vaccinated on the arm and the girls on the outer surface of the thigh. Table II summarizes the incidence of lupoid reactions, all

\section{TABLE II}

LUPOID REACTIONS IN ONE INSTITUTION RELATED TO SITE OF VOLE BACILLUS VACCINATION

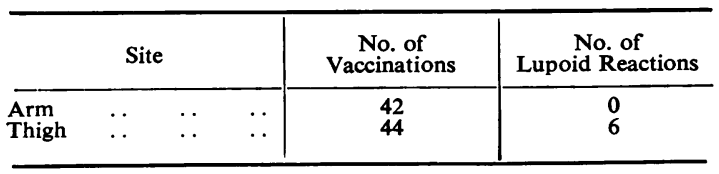

of which developed among the girls vaccinated in the thigh. This site is more open to trauma and secondary infection.

\section{The Relation of Lupoid Reactions to the Dosage of Vole Bacilli}

The dose of vole bacilli injected into the skin by multiple puncture varies with the density of the suspension of bacilli in the vaccine. Suspensions varying from $1 \mathrm{mg}$. moist weight of bacilli per $\mathrm{ml}$. to $5 \mathrm{mg}$. per $\mathrm{ml}$. have been used. Table III shows that the incidence of lupoid reactions increases with the density of the vole bacillus suspension.

TABLE III

NUMBER OF LUPOID REACTIONS RELATED TO THE STRENGTH OF VOLE VACCINE

\begin{tabular}{|c|c|c|c|}
\hline \multicolumn{2}{|c|}{$\begin{array}{c}\text { Strengths } \\
\text { of Vaccine (mg./ml.) }\end{array}$} & \multirow{2}{*}{$\begin{array}{c}\begin{array}{c}\text { No. of } \\
\text { Vaccinations }\end{array} \\
808 \\
311 \\
1,103\end{array}$} & \multirow{2}{*}{$\begin{array}{c}\begin{array}{c}\text { No. of } \\
\text { Lupoid Reactions }\end{array} \\
50(6 \cdot 2 \%) \\
12(3 \cdot 9 \%) \\
12(1 \cdot 1 \%)\end{array}$} \\
\hline $\begin{array}{l}5 \\
2.5 \text { or } 3 \\
2 \text { or less }\end{array}$ & $\begin{array}{l}\cdots \\
\cdots \\
\cdots\end{array}$ & & \\
\hline
\end{tabular}

\section{Lupoid Reactions in Mongolian Defectives}

Mongolism has long been thought to be a form of mental deficiency unusually susceptible to infection in general (Ireland, 1877 ; Tredgold, 1908) and to tuberculosis in particular (Engler, 1949). Table IV shows that a materially higher proportion of mongolian than of other defectives developed

TABLE IV

NUMBER OF LUPOID REACTIONS IN MONGOLIAN DEFECTIVES

\begin{tabular}{|c|c|c|}
\hline & $\begin{array}{c}\text { No. of } \\
\text { Vaccinations }\end{array}$ & $\begin{array}{c}\text { No. of } \\
\text { Lupoid Reactions }\end{array}$ \\
\hline $\begin{array}{l}\text { Mongolian defectives } \\
\text { Other defectives ... }\end{array}$ & $\begin{array}{r}157 \\
2,065\end{array}$ & $\begin{array}{l}20(12 \cdot 7 \%) \\
54(2.6 \%)\end{array}$ \\
\hline
\end{tabular}

the lesion after vaccination. A further factor which must be considered in this apparent predisposition to lupoid formation in mongolian defectives is the peculiar texture and histology of the skin ; this, rather than any inherent increased susceptibility to tubercle bacilli, may favour the production of this lesion.

\section{Treatment of Lupoid Reactions}

Most lupoid reactions seem to require active treatment sooner or later, mainly on account of their vulnerability to trauma with subsequent breakdown and reinfection, but also because of their unsightly appearance. Only a very small proportion subside and cicatrize spontaneously.

The lower grade mentally defective children constitute by far the largest group in which lupoid reactions have developed, and in one institution 35 out of 450 developed this complication. These were of varying extent and severity, although the greater proportion showed coalescent involvement of most or all of the vaccinated area. One lesion was very severe indeed, repeatedly breaking down and showing the rare tendency to spread widely into the adjacent skin beyond the original area of vaccination.

Since there was a clinical and histological similarity between these lesions and those of lupus vulgaris, and since these lupoid reactions were of similar origin, age, and degree, it was thought that the group might present a useful series in which to test the value of the administration of old tuberculin together with the established treatment of tuberculosis. Workers in Oxford (Smith, Vollum, and Cairns, 1948 ; Swithinbank, Smith, and Vollum, 1953) have shown that in tuberculous meningitis, especially where tuberculin sensitivity is well established, concomitant administration of tuberculin greatly enhances the efficacy of existing antituberculosis drugs. On a small series of six cases lupus vulgaris was similarly treated with encouraging results (Smith, 1953). This may be explained by the capacity of tuberculin to produce hyperaemia in sensitized tissue, particularly in tuberculous tissue itself, thus increasing the local concentration of the drugs. This has been confirmed in several experiments in intact animals (Sanders, Wells, and Wylie, 1949 ; Bosanquet, Daniel, and Vollum, 1953 ; Dodson, 1952).

The 21 most severe lupoid reactions were divided into two treatment groups while a further group of 13 patients with less extensive lesions received no treatment.

The two treatment groups are designated $\mathrm{A}$ and $B$ and the untreated control group $C$. In selecting groups A and B an attempt was made to divide the patients so that each group contained reactions of roughly comparable severity. Nevertheless, the most severe reactions were included in group $\mathbf{A}$, 
as it was hoped to clear these up as soon as possible.

At the time these observations were made isonicotinic acid hydrazide (isoniazid) was not available, otherwise it would have been included in the basic treatment of both groups $A$ and $B$ in addition to streptomycin, since several writers have now shown that an essential synergism exists between the two agents (Mackaness and Smith, 1953 ; Medical Research Council, 1952 ; Joiner, MacLean, Chalmers, Anderson, Collard, King, and Knox, 1953).

Group A comprised 11 children, six boys and five girls. The lesions varied in degree from a very large active lesion (the largest in this series) to a lesion showing scarring with only a few active nodules.

Group B was composed of 10 children; four boys and six girls.

Group C comprised five girls and eight boys. The lesions were on the whole less extensive than those in groups $A$ and $B$ but had shown no tendency to regress in two years.

\section{Treatment Programmes}

Group A.-Streptomycin was given twice daily during the whole course of treatment by intramuscular injection. Dosage was calculated according to body weight. The smallest dose was $0.4 \mathrm{~g}$. and the largest $1.4 \mathrm{~g}$. daily.

Para-aminosalicylic acid (P.A.S.) was given by mouth in the form of a mixture. Initial dosage was $1 \mathrm{~g}$. thrice daily and this was subsequently increased to $2 \mathrm{~g}$. and $3 \mathrm{~g}$. thrice daily in the case of some of the larger children, three weeks after the beginning of the treatment.

After a Mantoux test, old tuberculin (O.T.) was given intramuscularly every fourth day in increasing dosage until a general or local reaction was noted. In the absence of any reaction or in the presence of a doubtful reaction the dose was usually doubled. If the reaction was mild the dose was increased by $50 \%$. If the reaction was brisk the same dose was repeated on the next occasion or very rarely the next dose was omitted.

As treatment progressed experience with the highly individual reactions of the patients led to a more flexible variation of dosage. The maintenance of local reactions of moderate intensity and the avoidance of severe local or general reactions were the aims. It was found much more difficult to maintain moderate local reactions than to avoid more severe reactions.

The initial dose in all cases was $0.5 \mathrm{ml}$. of a 1 in 10,000 dilution of O.T. and this was increased through dilutions of 1 in $1,000,1$ in 100,1 in $\overrightarrow{00}$ to pure O.T. The highest single dose was $0.4 \mathrm{nu}$. of undiluted O.T. which six patients received, whipe the lowest final dose was $1.6 \mathrm{ml}$. of 1 in 190 dilution in one patient.

Most patients received 18 injections over $\omega_{a}$ period of 67 days.

Group B received streptomycin twice daily $\overrightarrow{\mathrm{b}}$ intramuscular injection and P.A.S. three timesog

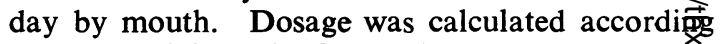
to body weight as in Group A.

No old tuberculin was given.

Group $C$ received no treatment and, as indicated above, comprised on the whole the least extensife lesions.

\section{Reactions to Old Tuberculin}

Local REACTIONS IN THE LUPOID.-The lesiog in groups $A$ and $B$ were inspected at not less than daily intervals. No reactions occurred in gromp B lesions. The temperature of all patients was taken morning and evening. All patients hadơ chest radiograph before beginning treatment. Mantoux testing was performed before and affrr treatment in all cases.

Injections of O.T. in group A resulted increased vascularity with swelling of the actiôse "apple jelly" nodules and erythema of the sir. rounding skin. In many cases the most sensitife indication of reaction was the increase in warm of the lesion best appreciated with the back of the examining hand. Reactions occurred in six to 4 hours after injection with O.T. and subsided within 24 hours of their appearance. Often the lesions scaled afterwards, in some cases without a other detectable change in the activity of the lupoid. Fleeting and unobserved vascular actions could not be excluded.

After the first four to five weeks of treatme almost all patients receiving O.T. developed a persistent goose skin appearance in the skin surrounding the nodules. These small papules appeared $\bar{q}_{0}$ affect the hair follicles which assumed a promnence and roughness more easily appreciated $\mathbb{B y}^{\prime}$ touch. The condition was considered to be vely similar to lichen scrofulosorum. These changs subsided slowly in the months after treatment with O.T. had been stopped.

General Reactions.-General reactions to jections of O.T. were not common. They consisted of a rise of temperature to $100^{\circ}-101^{\circ}$ है., and in a few cases the patient vomited and seemed to have headache. The low intellectual level of Re patients made it impossible to obtain any simjective account of their feelings. The reaction 
occurred within eight to 24 hours. Eight patients of the 12 in group A showed a general reaction at some stage of the treatment. In only two patients, the two oldest girls in group A, did general reactions occur repeatedly. In one of these girls 12 , and in the other five, of the 18 injections provoked general reactions. No general reactions were noted in patients not receiving O.T.

Classification of Reactions.-Reactions to injection of O.T. were classified as general or local, and the local reactions were further graded as doubtful, mild, or brisk. These subjective assessments were all made by the same observer (D.H.B.) and are probably consistent. Some "doubtful" reactions reported early in the treatment, before the nature of the reactions was known, may have been determined by the expectant attitude of the observer.

Sensitivity to O.T. varied considerably. The local reaction was maintained with ease in the lupoid reaction of only one patient (who was subsequently shown to have been incompletely desensitized to O.T.). In this case fractional increases in tuberculin dosage were sufficient to maintain local reactions. In other cases reactions could be maintained for a period by doubling the dose of tuberculin. Then quite suddenly sensitivity would disappear and no further reaction was provoked until the dose had been increased four- or sixfold. One patient showed no local reaction until a large dose of tuberculin, $1.8 \mathrm{ml}$. of 1 in 100 dilution, had been given. Four cases, however, showed a local reaction to $1.5 \mathrm{ml}$. of 1 in 10,000 O.T. The desensitization produced by parenteral tuberculin and the return of sensitivity after cessation of treatment is shown in Table V. Of Group A, who received parenteral tuberculin in addition to the standard therapy, all but two were desensitized to 1 in 100 O.T. in four months. The two exceptions both developed recrudescent lupoid lesions.

\section{Assessment of Results duRing TREATMENT}

The assessment of the slow healing changes in the lupoid reaction of groups $A$ and $B$ was difficult during treatment when the lesions were under daily observation. Nevertheless, we formed a strong impression that there was a more rapid initial healing of group $\mathrm{A}$, although this gain was less apparent when treatment was completed. Biopsies were performed before, during, and after treatment on selected patients in both groups. The impression of the more rapid regression in group $\mathrm{A}$ is strikingly confirmed by histological examination, significant improvement having oc-
TABLE V

VARIATIONS IN TUBERCULIN SENSITIVITY DURING TREATMENT OF LUPOID REACTIONS

\begin{tabular}{|c|c|c|c|c|c|c|}
\hline & \multicolumn{2}{|c|}{$\begin{array}{l}\text { Before Treatment } \\
\text { July, } 1951\end{array}$} & \multicolumn{2}{|c|}{$\begin{array}{l}\text { After Treatment } \\
\text { Nov., } 1951\end{array}$} & \multicolumn{2}{|c|}{ July, 1952} \\
\hline & $\begin{array}{l}\text { Dilution } \\
\text { O.T. }\end{array}$ & $\underset{(\mathrm{mm} .)}{\text { Oedema }}$ & $\begin{array}{l}\text { Dilution } \\
\text { O.T. }\end{array}$ & $\underset{(\mathrm{mm} .)}{\operatorname{Oedema}}$ & $\begin{array}{l}\text { Dilution } \\
\text { O.T. }\end{array}$ & $\underset{(\mathrm{mm} .)}{\text { Oedema }}$ \\
\hline $\begin{array}{l}\text { Group A : } \\
\text { M. T. B. } \\
\text { S. B. } \quad \cdots \\
\text { M. C. } \quad \cdots \\
\text { D. B. } \quad \cdots \\
\text { A. K. } \quad \cdots \\
\text { S. J. H. } \\
\text { I. M. O. } \\
\text { S. G. G. } \\
\text { D. J. H. } \\
\text { R. G. D. W. } \\
\text { D. T. D. }\end{array}$ & $\begin{array}{l}1 / 10,000 \\
1 / 10,000 \\
1 / 10,000 \\
1 / 10,000 \\
1 / 10,000 \\
1 / 10,000 \\
1 / 10,000 \\
1 / 10,000 \\
1 / 10,000 \\
1 / 10,000 \\
1 / 10,000\end{array}$ & $\begin{array}{r}6 \\
11 \\
7 \\
9 \\
8 \\
7 \\
6 \\
8 \\
15 \\
15 \\
7\end{array}$ & $\begin{array}{l}1 / 100 \\
1 / 100 \\
1 / 100 \\
1 / 100 \\
1 / 100 \\
1 / 100 \\
1 / 100 \\
1 / 100 \\
1 / 100 \\
1 / 100 \\
1 / 100\end{array}$ & $\begin{array}{r}0 \\
0 \\
0 \\
0 \\
0 \\
0 \\
0 \\
0 \\
10 \\
8 \\
0\end{array}$ & $\begin{array}{r}1 / 10,000 \\
1 / 10,000 \\
1 / 100 \\
1 / 10,000 \\
1 / 100 \\
1 / 100 \\
1 / 100 \\
1 / 100 \\
1 / 10,000 \\
1 / 100 \\
1 / 100\end{array}$ & $\begin{array}{r}7 \\
10 \\
7 \\
6 \\
6 \\
6 \\
6 \\
8 \\
9 \\
13 \\
9\end{array}$ \\
\hline $\begin{array}{l}\text { Group B: } \\
\text { J. M. P... } \\
\text { B. D. C. } \\
\text { R. D. D. } \\
\text { C. I. S. . } \\
\text { E. S. } \cdots \\
\text { L. J. W. } \\
\text { V. E. F... } \\
\text { A. M. B. } \\
\text { G. J. McC. } \\
\text { F. E. W. }\end{array}$ & $\begin{array}{l}1 / 10,000 \\
1 / 10,000 \\
1 / 10,000 \\
1 / 10,000 \\
1 / 10,000 \\
1 / 10,000 \\
1 / 10,000 \\
1 / 10,000 \\
1 / 10,000 \\
1 / 10,000\end{array}$ & $\begin{array}{r}7 \\
15 \\
5 \\
7 \\
9 \\
5 \\
10 \\
9 \\
9 \\
15\end{array}$ & $\begin{array}{c}1 / 10,000 \\
1 / 10,000 \\
1 / 10,000 \\
1 / 10,000 \\
1 / 10,000 \\
1 / 10,000 \\
1 / 10,000 \\
1 / 10,000 \\
1 / 10,000 \\
-\end{array}$ & $\begin{array}{r}14 \\
18 \\
10 \\
15 \\
13 \\
15 \\
8 \\
9 \\
13 \\
-\end{array}$ & $\begin{array}{r}1 / 10,000 \\
1 / 10,000 \\
1 / 10,000 \\
1 / 10,000 \\
1 / 10,000 \\
1 / 10,000 \\
1 / 10,000 \\
1 / 100 \\
1 / 10,000 \\
1 / 10,000\end{array}$ & $\begin{array}{r}7 \\
14 \\
10 \\
10 \\
7 \\
10 \\
7 \\
15 \\
7 \\
13\end{array}$ \\
\hline $\begin{array}{l}\text { Controls : } \\
\text { M. A. } \quad \cdots \\
\text { M. A. } \quad \cdots \\
\text { E. B. } \quad \cdots \\
\text { R. B. } \quad \cdots \\
\text { G. C. } \quad \cdots \\
\text { W. C. } \quad \cdots \\
\text { M. D. } \quad \cdots \\
\text { D. P. } \quad \cdots \\
\text { D. S. } \quad \cdots \\
\text { W. S. } \quad \cdots \\
\text { P. V.-A. } \\
\text { V. W. } \quad \cdots \\
\text { D. B. } \quad \cdots\end{array}$ & $\begin{array}{r}1 / 10,000 \\
1 / 10,000 \\
1 / 10,000 \\
1 / 10,000 \\
1 / 10,000 \\
1 / 10,000 \\
1 / 10,000 \\
1 / 100 \\
1 / 10,000 \\
1 / 10,000 \\
1 / 100 \\
1 / 10,000\end{array}$ & $\begin{array}{r}9 \\
8 \\
8 \\
8 \\
9 \\
17 \\
10 \\
13 \\
10 \\
11 \\
6 \\
8 \\
13\end{array}$ & $\begin{array}{l}\text { This } \\
\text { not } \\
\text { at } \\
\text { tir }\end{array}$ & $\begin{array}{l}\text { group } \\
\text { tested } \\
\text { this } \\
\text { me. }\end{array}$ & $\begin{array}{r}1 / 10,000 \\
1 / 100 \\
1 / 10,000 \\
1 / 10,000 \\
1 / 10,000 \\
1 / 10,000 \\
1 / 10,000 \\
1 / 10,000 \\
1 / 10,000 \\
1 / 10,000 \\
1 / 10,000 \\
1 / 10,000 \\
1 / 10,000\end{array}$ & $\begin{array}{r}11 \\
14 \\
11 \\
7 \\
12 \\
11 \\
6 \\
10 \\
11 \\
12 \\
11 \\
10 \\
9\end{array}$ \\
\hline
\end{tabular}

curred in the group after one month and a normal skin histology being seen after three months.

Figs. $1-4$ are biopsy sections, taken at the start of the regimen and after one, two, and three months respectively, from a patient treated with tuberculin in addition to streptomycin and P.A.S. Figs. 5-7 are biopsy sections, taken at the start and after two and five months' treatment, from a case treated with the standard regimen without tuberculin. The slower improvement is confirmed histologically. Fig. 8 shows a section from an untreated control case at the finish of the trial. All sections were stained with haematoxylin and eosin. Sections stained in addition by the ZiehlNeelsen method invariably failed to show the presence of acid-fast tacilli.

The actual excision of a biopsy specimen produced striking local improvement, but, as all groups were thus investigated, the differences would appear valid.

As mentioned above, the administration of O.T. parenterally in addition to producing the desired increase in local vascularity also produced some 


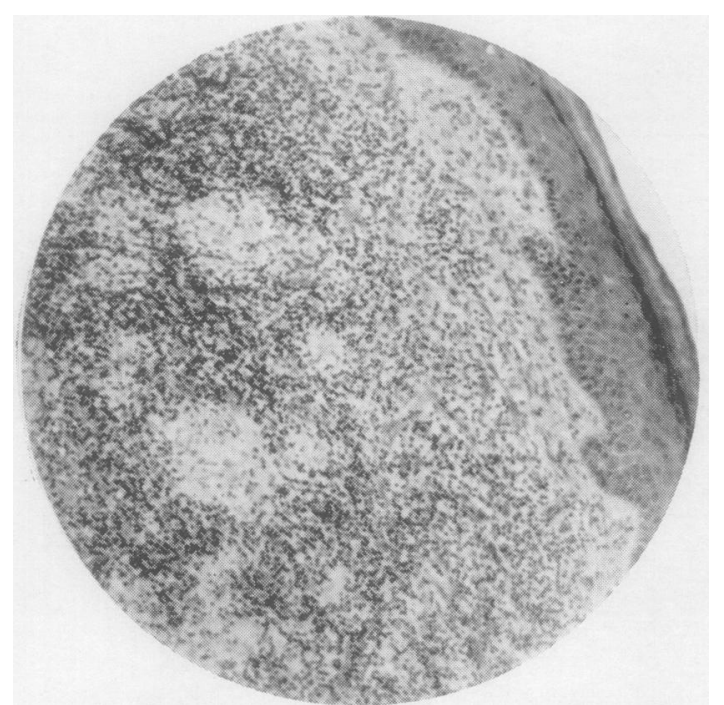

Fig. 1.-Lupoid lesion before starting treatment with streptomycin, P.A.S. and tuberculin.

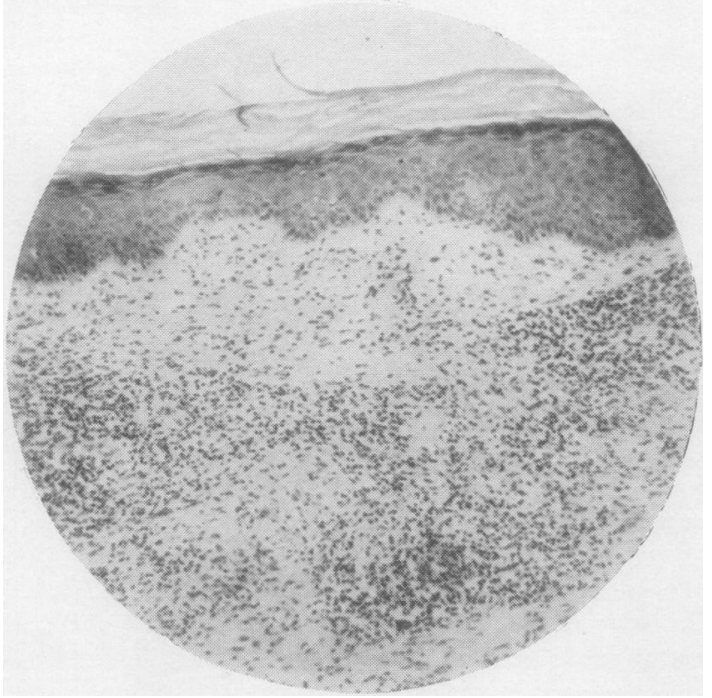

FIG. 3.-Lupoid lesion after two months' treatment with streptomycin, P.A.S., and tuberculin.

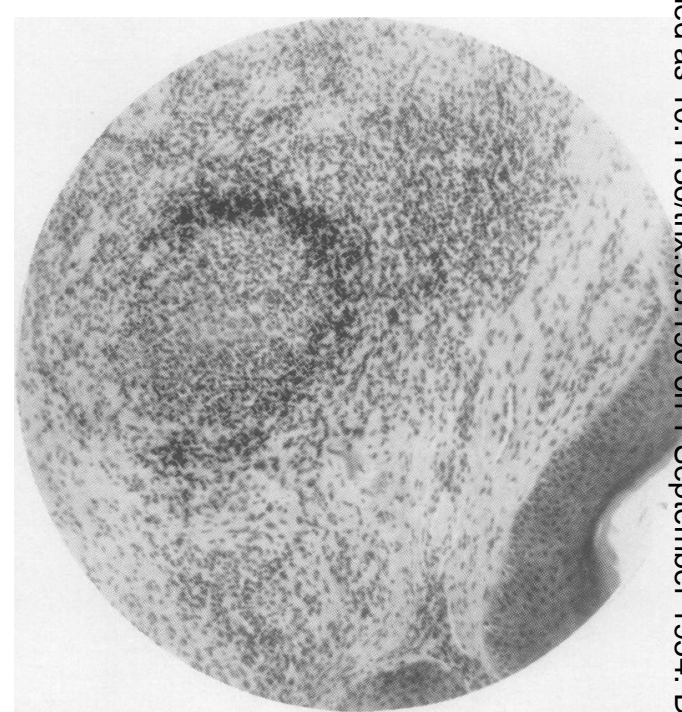

Fig. 2.-Lupoid lesion after one month's treatment with streptomyci P.A.S., and tuberculin.

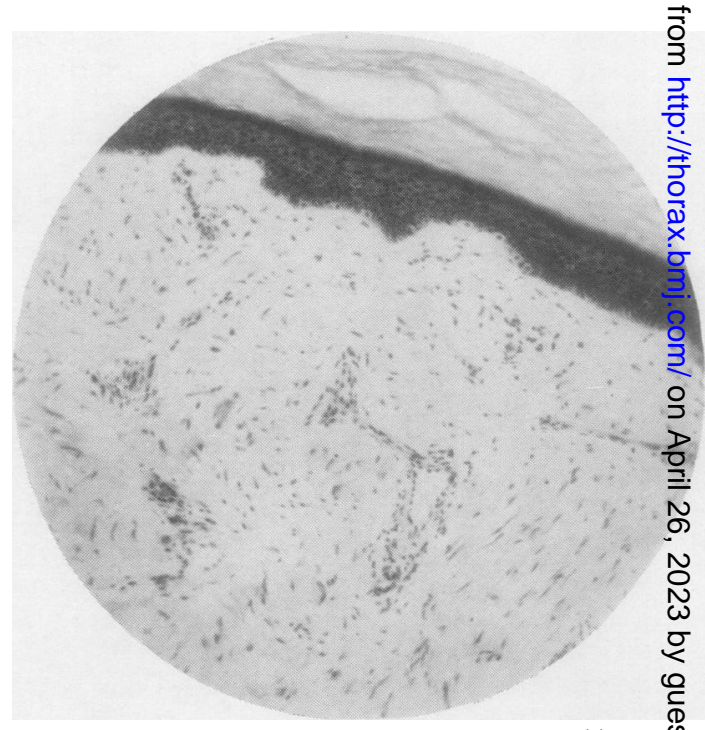

FIG. 4.-Lupoid lesion after three months' treatment with streffomycin, P.A.S., and tuberculin. 


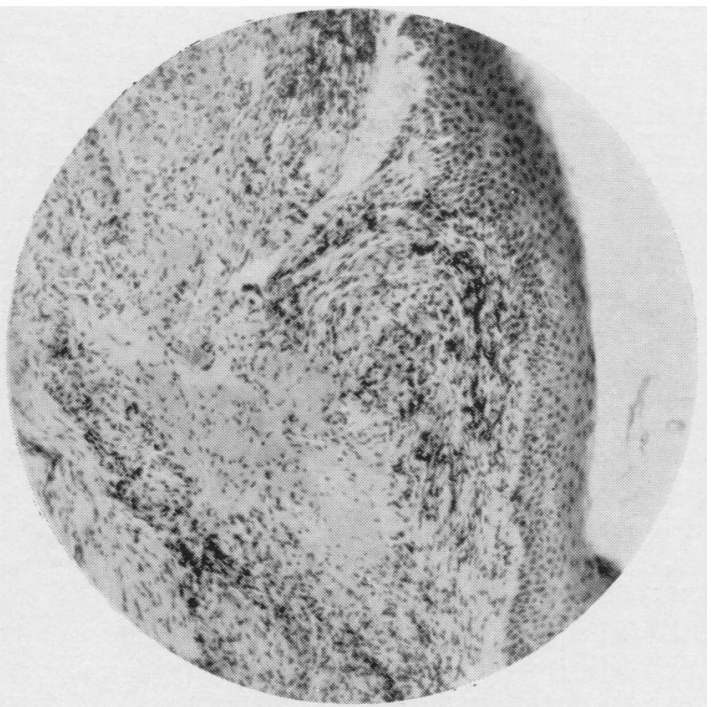

Fig. 5.-Lupoid lesion before the start of treatment with streptomycin and P.A.S. alone.

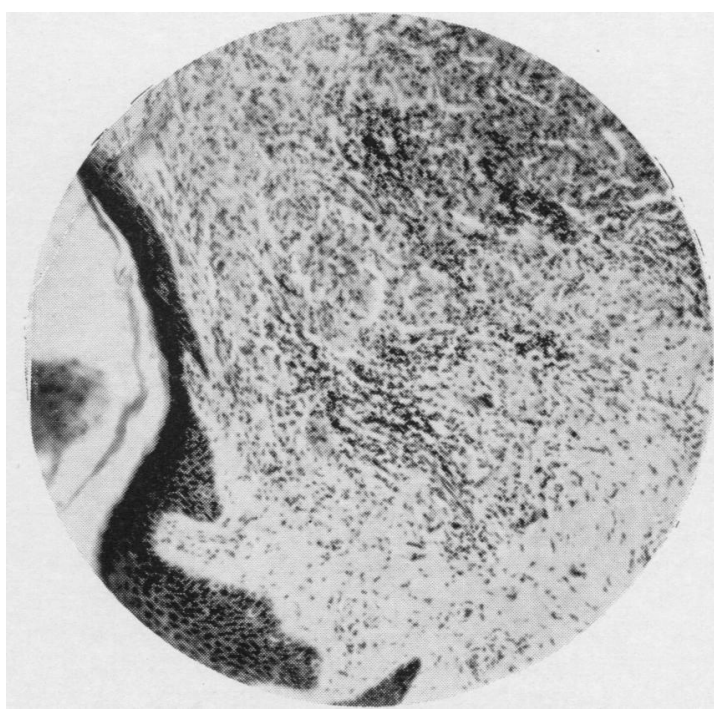

Fig. 6. - Lupoid lesion after two months' treatment with streptomycin and P.A.S. alone.

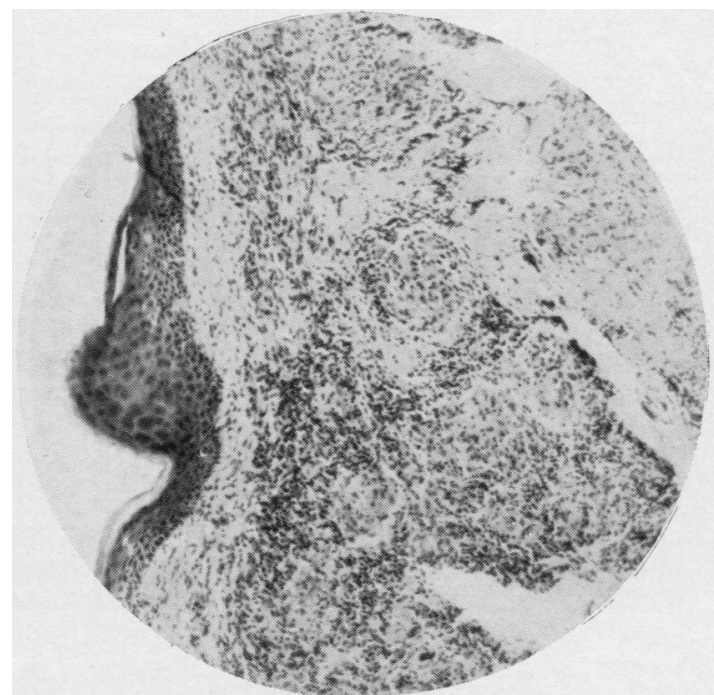

FiG. 8.-Control untreated lupoid lesion at the end of the trial. 
degree of desensitization. In all cases resensitization has occurred, although only two patients have developed a recurrence of lupoid and in neither of these was complete desensitization achieved.

\section{Other Methods of Treatment}

In a few cases slow improvement of the local lupoid reaction has been shown to occur after the administration of "calciferol," 50,000 units twice daily for a month. The numbers treated by this method are small and the results inconsistent. Probably the value of this treatment is similar to that of ultra-violet radiation, but we have so far inadequate experience to express a valid opinion on this point.

\section{Discussion}

Vaccination by multiple puncture has been used on all the patients concerned in this report. Birkhaug (1944), who first introduced the multiple puncture technique, found that the vole bacillus in smaller doses gave rise to rather more persistent scars than B.C.G. when administered by the same route. This has been confirmed recently (Hall and Wylie, 1952), who report a higher degree of tuberculin sensitivity with vole bacillus vaccination. Workers with B.C.G. have found that when this is inoculated in an area potentially liable to secondary infection and trauma the development of undesirable complications is higher. This has been noticed particularly in infants who have been inoculated in the "napkin area." Examination of the discharged or aspirated necrotic material obtained from the regional lymph nodes in such cases has often yielded a coliform bacterium in culture (Hall, 1952). Similarly, in the comparatively few cases in which the intradermal route has been employed in vole bacillus vaccination, regional lymph node involvement has been more often seen when the thigh has been used as the inoculation site or when extensive acneiform skin lesions were present.

Regional lymph node involvement after vaccination by multiple puncture with either vole bacillus or B.C.G. is rare, only four out of over 2,000 cases vaccinated having developed abscesses which either had to be aspirated or broke down spontaneously. Two out of the four, both female, were vaccinated in the thigh, and both the other two, although vaccinated in the arm, had evidence of skin sepsis. In no case was the local vaccination mark abnormal.

The programme of treatment outlined above was, of course, complicated by the desire to observe whether tuberculin administered in cont? bination with chemotherapeutic and antibiot drugs produced a synergistic effect, and this coulf be advantageously studied in tuberculous lesiorß of the same age and origin. It was satisfactory to observe that in all but the most severe cass those treated in both groups cleared up well. The group receiving parenteral tuberculin in additiocm to the standard treatment included on the whore those with the more extensive lesions, in spite of which, however, the improvement in this groug was more rapid. This is in accordance with expeca tation, as the action of tuberculin is to produce a hyperaemia most marked in and around tubeo culous tissue, which might be expected to result in the appearance of a higher concentration of any chemotherapeutic agent or antibiotic in th: area where their maximum effect is desirable. 审 tuberculous meningitis a similar beneficial syne 3 gistic action has been observed (Smith and Vollunt, 1950).

Whether the additional discomfort of the parent teral administration of tuberculin is justified by the rather more rapid rate of healing of the lesions is open to question. In this condition, howeve it seems probable, as the lesions are always supen ficial, that the injection of tuberculin could bo replaced by the local application of a tuberculi ointment or jelly. This would achieve the desired local and specific hyperaemia and presumabß avoid not only the inconvenience of a further in jection, the effect of which has to be watched carefully, but also the rare but undesirabe sequelae of pyrexia, headache, and vomiting.

Finally, it seems in most cases it should be pos sible to avoid lupoid reactions by guarding againg trauma and secondary infection ; first by avoidin the thigh as a site of vaccination, secondly bo preventing scratching, and finally by prompt control of secondary infection should it occur. $\mathrm{O}_{\overline{\mathrm{T}}}^{\mathrm{O}}$ these grounds extensive acne or other chronic skid infection is probably a contraindication to vaccina: tion unless the attendant risk of primary tubef culosis heavily outweighs this consideration. N

In our opinion there is no question of the lupoing reaction here described constituting a valid objees tion to the use of vole bacillus as an antigen active immunization against tuberculosis, as the conditions in which it arises can in nearly all cas be avoided. A condition which from its descrip. tion seems to be similar in some respects to that described here has been observed after vaccinatio with B.C.G. (Mimouni, 1951 ; Kalkoff, 1950), ang at least one case of considerably greater severity than we have observed after vole bacillus vaccine tion (Lomholt, 1947). 


\section{SUMMARY}

An unusual local complication of multiple puncture vaccination with vole bacillus is described and is called here the lupoid reaction. Histologically this lesion is a typical non-caseous tuberculous lesion, though vole bacilli have not been isolated from it. Lupoid reactions have occurred only in mental defectives, and show a close correlation with trauma in the eruptive stage and subsequent secondary infection.

The lupoid lesion is unsightly and of remarkable chronicity, rarely resolving spontaneously. Treatment with streptomycin parenterally and P.A.S. by mouth with or without parenteral tuberculin produced resolution in all but two severe cases which have relapsed. The cases successfully treated with tuberculin cleared more rapidly than those receiving streptomycin and P.A.S. alone. Those lintreated over the same period showed no improvemient.

Emphasis is placed upon the essential preventability of most, if not all, cases of lupoid reaction by avoiding the predisposing causes of infection and trauma.

We wish to thank our colleagues, Dr. R. L. Vollum and Dr. Honor Smith, for their advice and guidance in the tuberculin therapy, and Dr. Alice Carleton for assessing the progress of the cutaneous lesions; Dr. L. T. Hilliard, Medical Superintendent, and the staff at the Fountain Hospital for cooperation in this research; and Dr. A. Q. Wells for his valuable criticism.

The very large quantity of P.A.S. used was generously supplied by Messrs. Wander \& Co. Ltd. The photomicrographs were made by Mr. B. H. Glass.

\section{ADDENDUM}

Since this work was completed over two years ago, and while it was being prepared for publication, a further series consisting of two groups, each of six patients, in whom the lupoid reaction was of approximately the same severity, were treated as suggested above with streptomycin and isoniazid and local application in one group with tuberculin jelly and in the other with a non-specific rubefacient, to determine whether the action of tuberculin might be achieved by a localized vasodilatation producing an increased concentration of the drugs at the site of the lesion. The result of this small series was that both groups improved equally well and equally rapidly. In one of the patients the treatment with the tuberculin jelly was interrupted, as on the first day of treatment the patient developed the exanthem of scarlet fever. The streptomycin and isoniazid were continued, and in fact this patient's lupoid reaction completely cleared within the week, thus providing unexpected confirmation of the hypothesis.

Also since the initial observation, one of us (J. A. H. W.) has observed this lupoid reaction in patients who are not mentally defective. In all cases, however, he is satisfied that there has been persistent intermittent trauma usually caused by tight-fitting, rough clothing. Some cases were observed in an orphanage, and one in a nurse who had attempted to disguise the eruption by covering it during the day with a tight-fitting sleeve of her uniform, and off-duty by the application of cosmetics.

While, of course, the recognition of this unsightly reaction in apparently normal people under certain conditions makes the objection to this technique more serious, it is nevertheless still not considered to be too great to permit in selected cases the use of the multiple puncture technique to administer the vole bacillus as an antigen. More recent investigations using the intradermal technique (Graham and others, to be published) suggest, however, that in the long run this method of administration may prove to be preferable to multiple puncture.

\section{RSFERENCES}

Birkhaug, K. (1944). Acta med. scand., 117, 274

Bosanquet, F. D., Daniel, P. M., and Vollum, R. L. (1953). Brit. J. exp. Path., 34, 376.

Dodson, L. (1952). Personal communication.

Engler, M. (1949). Mongolism, p. 109. Wright, Bristol.

Hall, I. M. (1952). Personal communication.

Hall, I. M. (1952). Personal communication. 608.

Ireland, W. W. (1877). On Idiocy and Imbecility. Churchill, London. Joiner, C. L., MacLean, K. S., Chalmers, D. G., Anderson, K., Collard, P., King M. B., and Knox, R. (1953).' Lancet, 2, 152.

Kalkoff, K. W.'(1950). Hautarzt, 1, 366

Lomholt, S. (1947). Acta derm. venereol. stockh., 27, 130.

Mackaness, G., and Smith, N. (1953). Amer. Rev. Tuberc., 67, 322.

Medical Research Council Report (1952). Brit. med. J., 2, 735.

Mimouni, J. (1951). Algérie méd., 55, 1138.

Sanders, A. G., Wells, A. Q., and Wylie, J. A. H. (1949). Quoted by Sanders, A. G., Florey, H W., and Wells. A. Q. (1951). Brit. J. exp. Path., 32, 455.

Smith, H. V. (1953). Proc. roy. Soc Med., 46, 588. and Vollum, R. L. (1950). Lancet, 2, 275.

- and Cairns, H. (1948). Ibid, 1, 627.

Swithinbank, J., Smith, H. V., and Vollum, R. L. (1953). J. Path. Bact., 65, 565.

Tredgold, A. F. (1908). Mental Deficiency. Baillière, Tindall \&

Wells, A. Q. (1946). S Spec. Rep. Ser. med. Res. Coun., Lond., No. 259. 